\title{
LOS TOLEDO CACEREÑOS (RAMA DE LA CASA DE OROPESA) Y SUS VINCULACIONES LOCALES EN LOS SIGLOS XIV, XV y XVI
}

\author{
Guillermo Alvarez de Toledo Pineda. \\ Universidad de Cádiz.
}

\section{$\underline{R E S U M E N}$}

Trato de estudiar genealógicamente una rama de la casa de Oropesa, asentada en Cáceres a finales del siglo XIV, con el objeto de situarla en la escala sociológica cacereña bajomedieval y renacentista, tras analizar su potencial económico y sus vinculaciones y entronques con la nobleza local y regional.

Palabras claves: Oropesa, Toledo, Cáceres, Golfines.

\section{$\underline{A B S T R A C T}$}

I try to study the genealogy one of the branch of the Oropesa hause, established in Cáceres at the end of XIV century, for locating between the caceres society, low-medieval and renaissance ages, after to be analised its economic potential and its ties and affinities with the local and regional nobility.

Keyword: Oropesa, Toledo, Cáceres, Golfines.

Metodológicamente abordo la cuestión a tratar de forma tripartita. Una primera, de marcado cariz genealógico, que por su diacronía permite situar a las personas aludidas en sus tiempos justos. Una segunda, de carácter pecuniario, intentando acercarme lo más posible a la realidad económica de las familias estudiadas. La tercera, en buena medida, reflejo y consecuencia de las anteriores, de claro signo sociológico. Lo considero método idóneo para lograr el objetivo propuesto: Situar a los Toledo en su justo lugar dentro de la escala sociológica cacereña bajomedieval y renacentista.

En tesis de licenciatura leída en la Facultad de Filosofía y Letras de la Universidad de Sevilla en junio de 1987, dirigida por Don Rafael Sánchez Mantero, analicé un linaje sevillano del antiguo régimen (Los Toledo-Golfin), de raíces cacereñas. Iniciaba mi estudio en Gutierre de Toledo, caballero cacereño del siglo XV, casado con Gracia de Carvajal, hija de Juan de Carvajal. Finalizaba 
en 1873, año en que muere Rafael Alvarez de Toledo y Maureta, último Mayorazgo de esta línea de los Toledo y descendiente directo de Gutierre. Supe entonces, documentalmente, que al menos cuatro generaciones de la familia habían nacido y vivido en Cáceres: la del citado Gutierre de Toledo, la de su hijo García Alvarez de Toledo, la de su nieto García de Paredes Toledo y la de su biznieto García de Toledo Ovando, quien terminaría afincándose en Cazalla de la Sierra, donde fallecerá.

Conocí al mismo tiempo, también documentalmente, que el linaje descendía por "linia reta de varon" de la Casa Condal de Oropesa, según Carta Ejecutoria otorgada por el Rey Felipe II, a través de la Chancillería de Granada, al mencionado García de Toledo Ovando, con fecha de 21 de Enero de 1576: "Venian e dezendian por linea reta de varon de los Condes de Oropesa", y "que se avian benido a bivir a la dicha villa de Caceres en el tiempo de las guerras e alteraciones entre castilla y portugal e que ansi era cosa publica e muy notoria den la dicha villa de caceres".?

Sostuve entonces la hipótesis (toda investigación es perfectible), que la guerra entre Castilla y Portugal aludida en la Carta Ejecutoria, егa la de la sucesión castellana acaecida tras la muerte de Enrique IV. Acorde con esta hipótesis, basada en mi interpretación del texto de la Ejecutoria, Gutierre de Toledo habria sido el primer miembro del linaje afincado en Cáceres. No era así. Gutierre de Toledo era hermano de Fernán Alvarez de Toledo, también conocido como Fernando de Toledo, Regidor de Cáceres al menos desde octubre de 14813. "Honrado cavallero"4. El Regidor Fernando de Toledo casó con Leonor de Ulloa, hija de Diego García de Ulloa, el rico, Señor de Media Cacha, y de Mencía Pérez de Ulloa

Ambos hermanos (Fernando y Gutierre), cuya casa se levanta en el Adarve cacereño, junto al Palacio Episcopal', eran hijos de García Alvarez de Toledo, casado con una hija de Alvar Sánchez de Figueroa y de Catalina Sánchez Durán ${ }^{7}$ y nietos de Fernán Alvarez de Toledo, Corregidor y Juez Mayor del Rey, en Cáceres, a fines del siglo XIV ${ }^{8}$, quien sí es el primer Toledo que se avecina en Cáceres.

\footnotetext{
1 D.F.C.E. Pássim.

${ }^{2}$ Ibid fol. 50.

${ }^{3}$ A.M.C.Doc, $n^{\circ}$ 144.0, 51 ; Libro de Ordenanzas, ff, 425 R-426V.

${ }^{4}$ Véase GARCíA OLIVA, M" Dolores, Documentación Histórica del Archivo Municipal de Cáceres (1475-1504), Cáceres, Ed, Institución cultural "El Brocense", 1988, p.163.

"SALAZAR Y ACHA, Jaime de, Los Alvarez de Toledo (opúsculo aún sin editar).

${ }^{6}$ HURTADO, P., Castillos, Torres y Casas Fuertes de la Provincia de Cáceres, Mérida, Ed, Regional de Extremadura, 1989, p.44.

7 SALAZAR Y ACHA, J, de, op. cit.

- Colección Salazar y Castro, Biblioteca de la Real Academia de la Historia, D-30, f.257v.
} 
Por consiguiente, las guerras entre Castilla y Portugal referidas en la Ejecutoria, en el transcurso de las cuales esta rama de los Toledo se traslada a Cáceres, son las guerras castellano-portuguesas surgidas tras la muerte del Rey Don Fernando de Portugal por el intento de Juan I de Castilla, casado con Doña Beatriz, heredera del trono portugués, de ser reconocido como monarca del país luso. Intento castellano fallido, como sabido es, al vencer Portugal a Castilla, el año 1385, en la batalla de Aljubarrota tras la cual es coronado Rey de Portugal el Maestre de Avís, con el nombre y orden de Juan I de Portugal.

Por tanto son seis, al menos, las generaciones de los Toledo naturalizados en la ciudad, por entonces villa, de Cáceres, donde nacerán, casarán y, en buen número morirán. Las siguientes:

Fernán Alvarez de Toledo, Corregidor de Cáceres, casado con Isabel de Saavedra, Señora de la Corchuela, que testa en 1415, hija de Alvar Méndez y de Elvira Martín. Este Fernán Alvarez de Toledo debió ser hijo, por razones cronológicas y onomásticas, si bien esta filiación no nos consta documentalmente, de Fernando Alvarez de Toledo, II Señor de Oropesa9. He de comentar sobre este punto, que cuando testa el II Señor de Oropesa, en esta Villa, el 18 de septiembre de 1398, ordena que le suceda en el Mayorazgo su hijo primogénito (García Alvarez de Toledo) y que sus bienes libres se repartan, a partes iguales, entre sus cuatro hijos ${ }^{10}$. A saber: El citado García, heredero del Señorío Oropesano, como Mayorazgo. Diego López de Ayala. Pedro Suárez de Toledo y Juan Alvarez de Toledo. No aparece en antedicho testamento su probable quinto hijo, Fernán Alvarez de Toledo, Corregidor de Cáceres. No obstante, en el inventario de bienes que la viuda del II Señor de Oropesa, Elvira de Ayala, ordena hacer el 26 de octubre de 1398 , se alude a la existencia de otro testamento, que al parecer dictó el II Señor de Oropesa y que, por desgracia, no se conserva actualmente en el Archivo Ducal de Frías, Casa que hoy día detenta el Condado de Oropesa ${ }^{11}$. Tal vez en este testamento perdido se mencionara a éste, muy probable, quinto hijo.

Hijo de Fernán Alvarez de Toledo y de Isabel de Saavedra fue García Alvarez de Toledo, que casó ("vida supra") con una hija de Alvar Sánchez de Figueroa y de Catalina Sánchez Durán (SEGUNDA GENERACIÓN). Los dos hijos de este matrimonio: Fernán Alvarez de Toledo y Gutierre de Toledo forman la TERCERA GENERACION de los Toledo cacereños.

\footnotetext{
"SALAZAR Y ACHA, J. de, op. cit.

"FRANCO SILVA, A, "Oropesa. El nacimiento de un señorío toledano a fines del sigio XIV", en Antario de Estudios Medievales, $\mathrm{n}^{\mathrm{0}} 15$, p. 307, Barcelona, Consejo Superior de Investigaciones Científicas, 1985.

"Ibid, p. 308.
} 
Frutos del matrimonio formado por el primero de los hermanos, Fernán Alvarez de Toledo (Fernando de Toledo), Regidor de Cáceres como más arriba se indica con Leonor de Ulloa, fueron:

A) García de Toledo, Caballero de San Juan.

B) Mencía de Toledo, casada con Juan de Carvajal, hija de Lorenzo de Ulloa, Señor de Malgarrida, y de Beatriz Morán.

C) Beatriz Alvarez de Toledo, mujer de Diego Becerra, Comendador de Santiago. ${ }^{12}$

Gutierre de Toledo (segundo hijo de García Alvarez de Toledo), contrajo matrimonio con Gracia de Carvajal, hija de Juan de Carvajal y de Marina Gutiérrez $^{13}$. Tres vástagos hubo del matrimonio:

A) García Alvarez de Toledo, del que volveré a escribir.

B) Ximena Alvarez de Toledo, de la que carezco de más información.

C) Marina Gutiérrez de Carvajal, que testó el 18 de agosto de 1503. Había contraído nupcias, hacia 1491, con Rodrigo de Ovando, hijo del Capitán Diego de Cáceres Ovando y de Isabel de Flores.

Los tres hijos de Fernán Alvarez de Toledo, más los tres de su hermano Gutierre de Toledo, componen la CUARTA GENERACION.

El Capitán Diego de Cáceres Ovando (suegro de Marina Gutiérrez de Carvajal), dueño de la Torre de la Cigüeña, única que se salvó en la villa de ser desmochada por Orden de la Reina Isabel, de 1477, en agradecimiento a los servicios de armas prestados por el Capitán a los Reyes Católicos en su lucha por el trono castellano, especialmente en la batalla de Toro ${ }^{14}$, testó en Valladolid el 13 de agosto de $1530^{15}$.

García Alvarez de Toledo, hijo de Gutierre de Toledo, se casa, sobre 1500 , con Elvira de Paredes, hija de García de Paredes y de Inés de Ribera ${ }^{16}$. Durante el movimiento y alteración de las Comunidades, García Alvarez de Toledo, junto a otros tres caballeros de los más principales y de más antigua nobleza (entre ellos su consuegro Francisco de Ovando, el galán) fue elegido Alcalde con vara de

\footnotetext{
SALAZAR Y ACHA, Jaime de, op. cit.

${ }^{13}$ D.F.C.E. Pássim.

${ }^{4}$ HURTADO, Publio, op. cit, p. 44.

"SALAZAR Y ACHA, Jaime de, op. cit.

${ }^{16}$ D.F.C.E. Pássim y SALAZAR Y ACHA, Jaime de, op. cit.
} 
Justicia para que rigiese y gobernase Cáceres en nombre del Rey Carlos I ${ }^{17}$. Hijo del anticomunero García Alvarez de Toledo y de Elvira de Paredes, fue García de Paredes Toledo, quien significa la QUINTA GENERACION.

García de Paredes Toledo, fallecido en Cáceres el 9 de marzo de 1566, fue enterrado en la Iglesia de Santa María. Había casado, antes del 12 de mayo de 1535, con María de Ovando Golfín, fallecida en Cáceres el 27 de diciembre de 1579, hija de Francisco de Ovando, el galán, y de Isabel de Torres Golfín ${ }^{18}$; y no de Diego Ovando y de Beatriz Cuello de Paredes Golfín como afirman los García Carraffa en su Enciclopedia Heráldica y Genealógica. Amplia fue la progenie del matrimonio formado por García de Paredes Toledo y María de Ovando Golfín. Con ella entramos en la sexta y probablemente ULTIMA GENERACION cacereña, por varonía, del linaje. La siguiente:

A) García de Toledo Ovando, de quien más abajo volveré a escribir con detalle en cuanto puede ser considerado el iniciador de la línea Toledo -Golfín.

B) Francisco de Toledo, nacido en Cáceres y casado en Cazalla, antes del 26 de agosto de 1566, con Beatriz Arias, hija de Antonio Caballero, natural de la misma Cazalla.

C) Elvira de Toledo, fallecida en Cáceres el 14 de septiembre de 1598. Elvira había estado casada con Juan Cano de Moctezuma, fallecido en Madrid el 2 de enero de 1579, hijo de Juan Cano de Saavedra y de Isabel de Moctezuma.

D) Aldonza de Torres, casada antes del 4 de marzo de 1551 con Sancho de Paredes, muerto en Cáceres el 20 de diciembre de 1601, hijo natural de Sancho de Paredes y de Mari Sánchez ${ }^{19}$. Un hijo de este matrimonio recibió el beneficio de una capellanía, por valor de 1.000 ducados, fundada por su tío Francisco de Toledo en Cazalla de la Sierra el 24 de mayo de $1599^{20}$.

E) Gracia de Carvajal, casada el 17 de noviembre de 1564 con Antonio de Sotomayor Bravo, Regidor Perpétuo de Cáceres, hijo de Francisco de Sotomayor y de Ana Bravo. Gracia muere en Cáceres el 14 de diciembre de 1607. Su marido había fallecido el 31 de octubre de 1573.

${ }^{17}$ D.F.C.E. Passim.

${ }^{18}$ Ibid. Pássim.

is SALAZAR Y ACHA, Jaime de, op, cit.

${ }^{20}$ D.F.A.T. F. 15. 
F) Isabel de Torres, bautizada en Cáceres el 26 de mayo de 1548 y casada en la misma ciudad (velaciones el 16 de noviembre de 1567 ) ${ }^{21}$, con su tío Hernando de Ovando y Paredes-Golfín, hermano de su madre, María de Ovando, quien fue I Señor de Zanarrillas, Caballerizo real y Comendador de Aguilarejo, de la Orden de Santiago ${ }^{22}$. Fueron hijos de este matrimonio, Diego de Ovando y Torre y Nicolás de Ovando y Torres, Caballero de la Orden de Santiago desde noviembre de 1594.

G) Hernando de Carvajal, bautizado en Cáceres el 11 de septiembre de 1549. Murió cautivo, en Constantinopla, antes de $1581^{23}$.

H) Fernando Alvarez de Toledo, tal vez el mayor, mencionado en escritura de venta de heredamientos de García de Toledo Ovando (su hermano) a Sancho de Paredes Sánchez, vecino de Cáceres, fechada en esta villa el 26 de mayo de 1572, ante el escribano Antonio Gutiérrez. Fueron testigos Antonio Palazuelos, Antonio Durán y Pedro Martínez, hijo de Benito Gómez, vecinos de Cáceres ${ }^{24}$. Carezco de más noticias sobre éste Fernando Alvarez de Toledo, hijo de García de Paredes Toledo y de María de Ovando Golfín. Ofrezco, sin embargo, los datos siguientes, como más arriba prometía, sobre su hermano García de Toledo Ovando, nacido en Cáceres alrededor de 1535 e iniciador de la línea Toledo-Golfín.

García de Toledo Ovando se casó y murió en Cazalla de la Sierra, villa en la que se avecina y afinca tras trasladarse a ella desde Cáceres con anterioridad al 9 de marzo de 1566 , fecha de fallecimiento de su padre.

Sobre este asunto dirá su nieto Fernando de Toledo-Golfín (hijo de Antonio de Toledo-Golfín), noventa años más tarde: "Don García Alvarez de Toledo (evidentemente se refiere a García de Toledo Ovando), mi abuelo que fue el primero que vino a esta tierra y se casó en ella"2.5. En efecto, casó el 27 de agosto de 1566 con Francisca de Gálvez, hija de Antonio Caballero, en Cazalla. El 21 de enero de 1576, tras pleitear con el Consejo cazallero, obtiene Carta Ejecutoria de nobleza, a través de la Real Chancillería de Granada. La preside el ajedrezado de los Alvarez de Toledo dividido en quinces escaques, ocho de plata y siete de azur, timbrado con corona, yelmo y lambrequines. El lema dice: MICHI ( ) RI GLO-

\footnotetext{
${ }^{21}$ SALAZAR Y ACHA, Jaime de, op. cit.

22 GARCÍA CARRAFFA, A. y MADRID, A., Enciclopedia Heráldica y Genealógica, 1919. Tomo correspondiente al apellido Ovando.

${ }^{23}$ SALAZAR y ACHA, op, cit.

${ }^{24}$ D.F.A.T. Fols. 1-6.

${ }^{25}$ A.N.C.S. Ar̃o, 1655. Fols. 125 y siguientes.
} 
RIA SIT CRUCE DOMINIS MAISSIMOS. Poco después muere. En febrero de 1576 ya había enviudado Francisca de Gálvez ${ }^{26}$.

Con anterioridad a la obtención de la Ejecutoria de hidalguía, García de Toledo había vendido, como más arriba indico, dos heredamientos con sus campos y tierras de labor, dehesas de prados, cercas con viñas, casas y caseríos, guardas y corralas, pastos y abrevaderos, por valor de 1.592 .292 maravedíes (4.246 ducados). Ambas heredades estaban en el término de Cáceres y contiguas. Una era la dehesa mayor del arroyo del pez. La otra limitaba con las dehesas de los caballos y con las heredades que están en el carril de los mineros. Con el camino real de la plata, con el puerto del Tresquilón, con las dehesas de la fuente del pueblo y de la lagartería, con la alberca de los frailes, con el camino de Torre Algaz... y otros linderos. Las compra Sancho de Paredes el 26 de mayo de $1572^{27}$.

Hijos del matrimonio formado por García de Toledo Ovando y Francisca de Gálvez, fueron: A) García de Toledo. B) Francisco de Toledo. C) Antonio de Toledo-Golfin, heredero de mayorazgos cacereños que detallaré. D) Aldonza de Torres y E) María de Paredes, nacidos todos ya en Cazalla ${ }^{28}$.

El traslado de la familia a Cazalla no supuso pérdida alguna de vinculaciones con Cáceres. Los vínculos contraídos por los Toledo durante dos siglos con rancios linajes cacereños, iban a repercutir en beneficio de Antonio de ToledoGolfin. Heredará dos mayorazgos. El instituido por Francisco de Torres, hijo del Regidor Fernando de Ovando y de Inés Alvarez, en Cáceres, el 1 de abril de $1504^{29}$. Francisco de Torres era hermano de Aldonza de Torres, mujer de García Golfin tatarabuelos, por línea femenina, de Antonio de Toledo-Golfín; y el fundado por el antedicho García Golfín, Regidor cacereño, en testamento datado el 15 de junio de $1517^{30}$.

Francisco de Torres testa ante el escribano Gregorio de Grajos. Ordena ser enterrado en la Iglesia de San Mateos, colación en la que vivía, cerca de la sepultura de su abuelo Alonso de Torres. Instituye capellanía y mayorazgo. Funda el vínculo a favor de su hijo Juan de Torres, sus hijos y descendientes con preferencia del mayor al menor y del varón a la hembra. A falta de éstos, a favor de su hija Teresa de Ovando, por el mismo orden. Después a favor de su otro hijo Fernando de Sotomayor y sus descendientes. En caso de no haberlos, como así fue, los

\footnotetext{
${ }^{26}$ A.H.N. Secc. Ordenes Militares, Calatrava, año, 1662. Expte, $\pi^{\circ} 2584$. F. 82, perteneciente a Don Nicolás de Toledo-Golfín y Vera.

${ }^{21}$ D.F.A.T. Fols. 1-6,

D.F.A.T. Fols. 8-17.

${ }^{29}$ D.F.G. F.64.

In Ibid. Fols. $1-14$
} 
derechos recaerían en su sobrino Pedro Alonso Golfín, hijo de García Golfín y de su hermana Aldonza de Torres ${ }^{31}$. A pesar de ser precedido Pedro Alonso Golfín, en el orden sucesorio, por tres candidatos con mejor derecho, los bienes amayorazgados que ahora enumeraré, ya habían revertido en él en septiembre de $1543^{32}$.

Desconozco el cúmulo de circunstancias que pudieran darse para llegar a tan remota posibilidad. Sé, no obstante, que Juan de Torres es excluido en posterior codicilo paterno. Francisco de Torres había contraído dos matrimonios. El primero con Catalina Juárez. El segundo con Catalina Gómez de Ovando. En ellos, además de Juan de Torres, Teresa de Ovando y Fernando de Sotomayor, tubo otros tres hijos: María de Torres, Inés y Gutierre ${ }^{33}$.

Enumero bienes inmuebles que vincula: Sus casas de las Seguras con las tierras de alrededor. La huerta de la dehesilla en la ribera de Cáceres y un huerto, junto a esta huerta, más la patronía de El Salvador. Francisco de Torres poseía otros bienes que no vincula. Entre ellos, la dehesa de la barquera y sus casas de la colación de San Mateo $^{34}$. Recuerda en su testamento a algunos criados y criadas: Inés González, ama, Catalina, Lorenzo y Catalina de Ceclavín.

El otro mayorazgo que hereda Antonio de Toledo-Golfín, es el fundado por el Regidor García Golfín, su tararabuelo, en fecha y lugar preindicados. García Golfín, hijo de Pedro Alonso Golfin y de Juana González de Escobar, casó con Aldonza de Torres, hermanastra del antes citado Francisco de Torres, cuya madre, Juana de Sotomayor, tenía enterramiento con capilla en la Iglesia de San Mateo.

García Golfín vivía, como su cuñado Francisco de Torres, en la colación de San Mateos. Sin embargo, en el testamento, ordena que lo entierren en su capilla del Monasterio de San Francisco $0^{35}$.

Funda el mayorazgo a favor de su hijo Pedro Alonso Golfin, mejorándolo en tercio y remanente de quinto y ordenando que sus herederos habrán de usar, de forma obligada, el escudo de armas de los Golfines (dos castillos y dos flores de lis en campo) y el apellido Golfín como principal. Otros hijos de García Golfín y de Aldonza de Torres, fueron: A) Isabel de Torres, mujer de Francisco de Ovando, el galán, abuelos maternos de García de Toledo Ovando ${ }^{36}$. B) Leonor de Sotomayor y C) Francisca de Torres, monja en el Convento cacereño de las Garrobillas.

\footnotetext{
${ }^{31}$ Ibid. F,12,

${ }^{31}$ Ibid. F.87.

"1. Ibid. F.75.

${ }^{34}$ Ibid. Fols.70-73.

${ }^{35}$ Ibid. F.3.

${ }^{36}$ Ibid. F. 14.Vta.
} 
Relaciono el conjunto de bienes que vincula en el testamento: Las casas en las que él, García Golfĩn, vivía, más otras casas, frente a ellas, que le legó su padre, Pedro Alonso Golfín. El tercio de la casa de Sáncho Gil, más otras casas, en la plaza de Cáceres, en los soportales, que fueron del judío Zayas Cohen ${ }^{37}$; y una huerta, un pedazo de viña y otro de dehesa. Las casas que fueron de Zayas Cohen, habían sido compradas por madre de García Golfín a una nieta del judío. Tenían por linderos las casas de Francisco Román, acensuadas a Fernando de la Cerda, por una parte. Por otra parte, las casas de Ruy López de Medina, acensuadas a Gonzalo de Figidio. Por delante, los soportales de la plaza pública de la villa.

La huerta se hallaba situada en la ribera, lindando, por un lado con huertas del clérigo Juan Alonso de Guzmán, y por el otro con la huerta y estanque del Monasterio de San Francisco. Por otra parte, hacia linde con la calleja llamada del cabo de arriba. La viña, en el término cacereño, estaba en Lintarizo. Lindaba con viñas de los hijos de Mingolla y con viñas que fueron de Juan de Carvajal el viejo $0^{38}$. García Golfín, al igual que su cuñado Francisco de Torres, tampoco olvida a sus criados en el testamento. A Teresa Jiménez lega 1.000 maravedíes. A Teresa de Porras, 500. A Ana otros mil. A Diego veinte misas rezadas, y a Juan de Alcántara otras tantas ${ }^{39}$. Antonio de Toledo-Golfin, en quien terminarán revirtiendo ambos mayorazgos a través del hijo de García Golfin y de Aldonza de Torres (Pedro Alonso Golfín, hermano de su bisabuela materna Isabel de Torres Golfín), los vende, con Licencia Real de Felipe III, el 30 de octubre de $1609^{40}$, por una cantidad nada despreciable: 3.123 .750 maravedies ( 8.330 ducados). Tanto esta cantidad como la que recibe García de Toledo Ovando de Sancho de Paredes Sánchez (1.592.292 maravedies), cuando vende dos heredamientos (antes descritos) en Cáceres tras morir su padre, permiten, de forma aproximada, efectuar cálculos hipotéticos en lo relativo al monto total de algunos capitales y, por tanto, sobre el potencial económico de sus poseedores.

En lo referente a los 3.123.750 de maravedies que recibe Antonio de ToledoGolfin al vender sus propiedades amayorazgadas no se debe perder de vista al siguiente supuesto. Los fundadores de uno y otro mayorazgo eran caballeros íntimamente ligados a la oligarquía municipal cacereña (García Golfin, Regidor y Francisco de Torres, hijo de Regidor), lo cual permite colegir que el alcance de sus fortunas fuese similar $y$, por consiguiente fuese también semejante el valor de los bienes que vinculan. Partiendo de este supuesto, cada conjunto de estos bien-

3 Ibid. Fols. 7-9.

${ }^{38}$ Ibid. F.8.

${ }^{19}$ Ibid. F.14.

${ }^{40}$ Ibid. F.36. 
es amayorazgados (considerando la subida de precios producida en el reino desde que se fundan hasta comienzos del siglo XVIII), podría valorarse en torno a los 4.165 ducados (1.561.875 maravedíes). Es evidente la división por dos. Teniendo en cuenta que las mejoras se efectúan en tercio y remanente de quinto, me permito sugerir que el cómputo total de bienes, tanto de Francisco de Torres como de García Golfin, alcanzaría, como mínimo, los 13.000 ducados (4.875.000 maravedíes).

En cuanto a la cantidad que reciben los hermanos García y Francisco de Toledo (1.592.292 maravedíes) al vender sus heredamientos, no vinculados, me permito el siguiente cálculo en caso de que García de Paredes Toledo no hubiese mejorado a alguno de sus ocho hijos y suponiendo que el producto de la venta significase el total de la herencia paterna que recibían ambos hermanos. Correspondería, sobre estas premisas, a cada uno, 796.146 maravedíes (2.123 ducados). Cantidad que teniendo a la vista la amplia descendencia de García de Paredes Toledo (ocho hijos) permite, como mínimo, asignarle un conjunto de bienes con valor próximo a los 17.000 ducados (6.375.000 maravedíes). Capital superior a los asignađos a Francisco de Torres y a García Golfín, si bien la fecha de fallecimiento de estos dos caballeros son notablemente anteriores, bajo el punto de vista de la subida de precios, que la de García de Paredes Toledo ( 9 de marzo de 1566).

En cualquier caso, tomando como indicadoras las cantidades calculadas, no está de más, para el establecimiento de posibles comparaciones, echar un vistazo a los datos que a continuación se exponen.

A principios del siglo XVI, en 1507, cuando aún no se había producido la desorbitada subida de precios defendida por Hamilton, sino muy moderada alza, el padre de Santa Teresa, el hidalgo Don Alonso Sánchez de Cepeda, con fana de hombre rico, poseía un capital cuyo monto total rondaba los 3.000 ducados $^{41}$. Marineo Sículo nos dice que, a comienzos del reinado de Carlos I, las rentas anuales del Duque de Alba se cifraban en 50.000 ducados. En 45.000 las del Marqués de Priego y en 10.000 las del Marqués de Villafranca. Ocho décadas más tarde, Pedro Núñez de Salcedo, en su manuscrito titulado: Relación de todos los Titulos que hay en España... ni uno más ni uno menos (1597-1600), vuelve a ofrecer las rentas anuales, asimismo en ducados, de los Títulos citados. Duque de Alba, 120.000. Duque de Medina-Sidonia, 170.000. Marqués de Priego, 110.000. Marqués de Villafranca, 50.000, Conde Oropesa, casa matriz de los Toledo cacereños, 40.000. Al menos, por término medio, en el plazo de ochenta años trans-

"I ELLIOTT, J.H., La España Imperial (1463-1716), Barcelona, Vicens Vives, 1976, p. 121. 
curridos entre las cifras dadas por Marineo Sículo y las ofrecidas por Núñez de Salcedo, las rentas se cuadruplican.

D. Ramón Carande Thovar, en su: Carlos Vy sus banqueros, nos informa de los precios de artículos de primera necesidad que regían en 1549. La arroba de aceite, 238 maravedíes. La de vino, 151. La de trigo, 755 maravedíes. La construcción de una galera alcanzaba un costo de 6.000 ducados. Continuar con datos y cifras sería tedioso. Los expuestos sirven para aproximarnos al potencial económico de los personajes analizados. Acorde con sus privilegiadas situaciones sociológicas en el marco urbano cacereño y tierras comarcanas.

Se hace diáfana, por tanto, la vinculación de los Toledo, desde fines del siglo XIV hasta fines del XVI, con los más antiguos, potentes y representativos linajes cacereños, miembros del cabildo municipal, componentes de una verdadera casta cerrada. En Cáceres, la pugna por pertenecer al cabildo originó la Concordia de 1477, mediante la cual la Reina Isabel estableció los Regidores en número de doce. A partir de ella, Ovandos y Carvajales pasaron a monopolizar, por mitad, el poder municipal ${ }^{42}$. Lo ejercieron con sabio equilibrio, consiguiendo el buen funcionamiento de la institución concejil en la vida de la ciudad ${ }^{43}$.

Miembros de esta poderosa oligarquía, directamente emparentada con los Toledo, fueron: Juan de Carvajal, suegro de Gutierre de Toledo. Rodrigo de Ovando, marido de Marina Gutierrez de Carvajal (hija de Gutierre de Toledo y de Gracia de Carvajal). Francisco de Ovando, el galán, suegro de García de Paredes Toledo, quien durante el movimiento de las Comunidades será elegido Alcalde con vara de justicia. Hernando de Ovando y Paredes-Golfin, casado con su sobrina Isabel de Torres (hija de García de Paredes Toledo) ${ }^{44}$. Asimismo fueron Regidores cacereños: Fernando de Ovando, padre del Francisco de Torres que funda Mayorazgo analizado en estas páginas. Antonio de Sotomayor Bravo, marido de Gracia de Carvajal (hermana de García de Toledo Ovando el que se traslada a Cazalla de la Sierra). Otros entronques establecidos por los Toledo en tierras de Cáceres, son: El matrimonio del Corregidor y Juez Mayor Fernán Alvarez de Toledo (primer miembro de la familia asentado en la villa), con Isabel de Saavedra, Señora de la Corchuela y el de su nieto Fernán Alvarez de Toledo, a su vez Regidor de la villa, que casa con Leonor de Ulloa, hija de Diego García de Ulloa, Señor de Media Cacha; o el de Mencía de Toledo con Juan de Carvajal, hijo de Lorenzo de Ulloa, Señor de Malgarrida. Reflejos, al mismo tiempo, de la

\footnotetext{
42 CARICOL SAMANIEGO, Milagros, Cáceres en los siglos XVII y XVIII, Cáceres, Diputación de Cáceres, Institución cultural "El Broncense", 1990, p. 90.

"4ÁNCHEZ PÉREZ, A.J, Cáceres, La vida municipal cacereña en el S. XVII, 1986.

4 Véase cuadro genealógico adjunto.
} 
relevancia de la familia en la sociedad cacereña, fueron: El honor de Caballero de San Juan de García de Toledo (hijo del Regidor Fernán Alvarez del Toledo acabado de citar) y el buen matrimonio contraído por su hermana Beatriz Alvarez de Toledo con Diego Becerra, Comendador de la Orden de Santiago. En el mismo sentido es digno de señalar que Aldonza de Torres, mujer de García Golfin (matrimonio al que se hace referencia de forma reiterada con anterioridad), era nieta de Gutierre de Sotomayor, Maestre de la Orden de Alcántara a mediados del siglo $\mathrm{XV}^{45}$ y sobrina-nieta de Juan de Sotomayor, igualmente Maestre de Alcántara ${ }^{46}$. Comendadurías, Corregidurías, Regidurías... son ejercidas en el marzo territorial cacereño por los Toledo y por los linajes con los que enlazan.

Elevados oficios y dignidades que permiten considerarlos como conspicuos arquetipos de la nobleza cacereña y de la alta Extremadura durante los siglos contemplados en este escrito. Símbolos de este lustre y preeminencia son las casaspalacios que ennoblecen la arquitectura civil cacereña, construidas, en buena parte, por miembros de la aristocracia local.

Descendientes directos de estos Toledo de Cáceres, los Toledo-Golfín, serán Caballeros Veinticuatro, Alcaldes Mayores y Maestrantes de Sevilla en los siglos XVII y XVIII ${ }^{47}$. Tradición gubernativa urbana que, en sentido cronológico, arranca con la Alcaldía Mayor y Alguacilazgo Mayor de la ciudad de Toledo, ejercidas por Illán Pérez y su hijo Esteban Illán, ascendientes del linaje, en el siglo XII, como aseguran Luís de Salazar y Castro y otros genealogistas de máximo crédito.

"D.F.C.E. F. 91, Vlta.

${ }^{45}$ HURTADO, Publio, op. Cit, p. 29.

"Sobre este tema puede consultarse mi tesis de Licenciatura: Un linaje sevillano del Antiguo Régimen: Los Toledo-Goljin. Inédita, Universidad de Sevilla, 1987. 


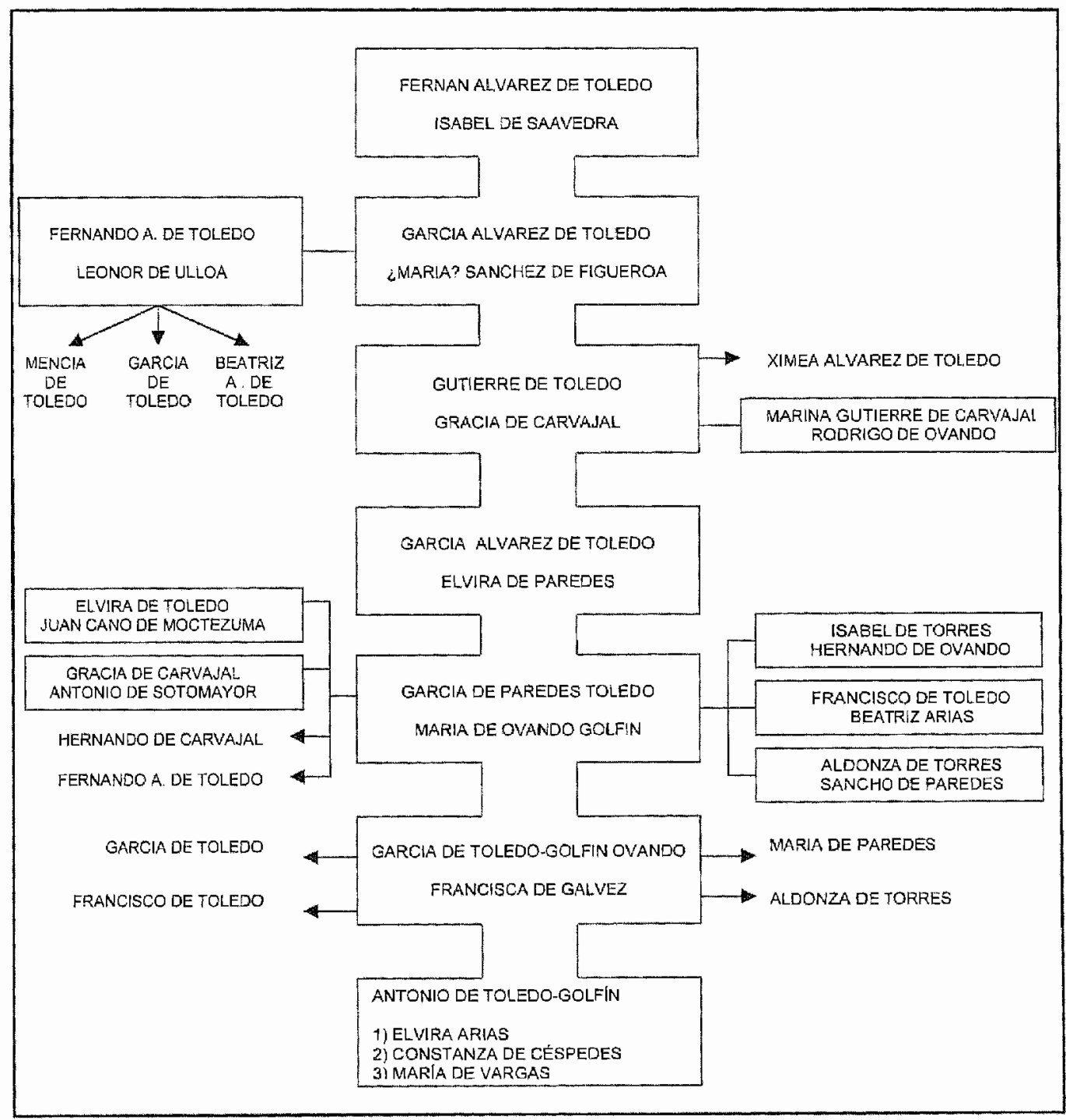

